\title{
Miscibility Behavior of Polyacrylamides Poly(Ethylene Glycol) Blends: Flory Huggins Interaction Parameter Determined by Thermal Analysis
}

\author{
Maria Elisa S. R. Silva ${ }^{1 *}$, Valdir Mano ${ }^{2}$, Raquel R. J. Pacheco ${ }^{1}$, Roberto F. S. Freitas ${ }^{1}$ \\ ${ }^{1}$ Department of Chemical Engineering, Federal University of Minas Gerais, Belo Horizonte, Brazil \\ ${ }^{2}$ Department de Natural Sciences, Federal University of São João del Rei, São João del Rei, Minas Gerais, Brazil \\ Email: *elisa@deq.ufmg.br
}

Received May 1, 2013; revised June 5, 2013; accepted July 3, 2013

Copyright (C) 2013 Maria Elisa S. R. Silva et al. This is an open access article distributed under the Creative Commons Attribution License, which permits unrestricted use, distribution, and reproduction in any medium, provided the original work is properly cited.

\begin{abstract}
Blends of polyacrylamide - PAM, poly(N-isopropylacrylamide) — PNIPAAm, poly(N-tert-butylacrylamide)—PTBAA, poly(N,N-dimethylacrylamide) - PDMAA and poly(N,N-diethylacrylamide) - PDEAA with poly(ethylene glycol) PEG were prepared by casting in methanol and water at concentrations of $20 \mathrm{wt} \%, 40 \mathrm{wt} \%, 60 \mathrm{wt} \%$, and $80 \mathrm{wt} \%$ in PEG. The miscibility of the components was studied by Differential Scanning Calorimetry-DSC. All blend systems are characterized by a single glass transition temperature $\left(T_{g}\right)$, close to the $T_{g}$ of the amorphous component. The Hoffman Weeks method was used to determine equilibrium melting temperature $\left(T_{m}\right)$ data. The determination of the melt point depression of the blends allowed the calculation of Flory-Huggins interaction parameter $\left(\chi_{12}\right)$ of the two polymers in the melt, by using the Nishi Wang equation. The interaction parameters, calculated for all the blends, are slightly negative and close to zero, suggesting a partial miscibility between the components.
\end{abstract}

Keywords: Polyacrylamides; Poly(Ethylene Glycol); Polymer Blends; Flory-Huggins Interaction Parameter; Differential Scanning Calorimetry

\section{Introduction}

Most of the proposed applications of polyacrylamides rely primarily on their behavior in aqueous solution [1-4]. On the other hand, this polymer and some of its N-alkyl substituted derivatives show great potential in the preparation of miscible polymer blends due to their ability to interact through hydrogen bonding. Polyacrylamide$\mathrm{PAM}$, and some of its $\mathrm{N}$-alkyl substituted derivatives, such as poly(N-isopropylacrylamide) — PNIPAAm, poly(N-tert-butylacrylamide) - PTBAA, poly(N,N-dimethylacrylamide) - PDMAA, and poly(N,N-diethylacrylamide) - PDEAA, are amorphous and water-soluble polymers with great industrial and agricultural interest [5-7]. In previous work, Silva et al. [8] showed that their thermal behavior is strongly dependent on the alkyl bonded to the amide group. Polyacrylamides form gels, or polymer networks that are able to expand in compatible solvent, like water, exhibiting a great potential for concentration of macromolecules from solutions, water purification, enzyme immobilization, drug delivery, sensors and

\footnotetext{
"Corresponding author.
}

for several biomedical uses [1,9-13].

Poly(ethyleneglycol), PEG, is a semi-crystalline polymer that shows applications as chromatographic support and polymeric electrolyte [14-18]. In the last ten years, interest has been attracted to systems in which at least one of the components is crystallizable. In this case, a melt point depression of the crystalline phase relative to its melting point $\left(T_{m}\right)$ in a non-interacting medium provides additional evidence of miscibility, since the kinetics and morphological effects over $T_{m}$ are eliminated [19]. Measurement of the melting temperature $\left(T_{m}\right)$ depression for blends allowed the determination of the Flory-Huggins interaction parameter $\left(\chi_{12}\right)$ of polymers in the melt state, by using the Nishi-Wang equation [20,21]. The Hoffman-Weeks method is used to determine the equilibrium data [22].

There have been many studies on miscible blends containing poly(ethylene glycol) and poly(ethylene oxide). For example, blends of $\mathrm{PEO} /$ poly(epichlorohydrin) and $\mathrm{PEO} /$ poly(epichlorohydrin-co-ethylene oxide) were studied by Silva et al. [19]. For these systems, the polymerpolymer interaction parameters are all negatives and ex- 
hibit dependence on the blend composition, decreasing for blends rich in PEO, suggesting that the polymer pairs are thermodynamically miscible.

Cortazar et al. [23] and Cimmino et al. [24] studied blends of PEO/poly(methyl methacrylate) with several molecular weights, finding $\chi_{12}$ values in the range of -0.131 to -0.290 . Blends of PEO $\left(\mathrm{M}_{\mathrm{W}}=2.0 \times 10^{3}\right)$ and poly(p-hydroxibenzoic acid)—PHB, $\left(\mathrm{M}_{\mathrm{W}}=2.79 \times 10^{3}\right)$ are miscible and exhibit $\chi_{12}$ values of -0.21 to -2.00 , depending on the concentration of the crystalline component [25].

The miscibility of PVC/PEO blends was studied using viscosimetry, thermal analysis and microscopy by Neiro et al. [26]. $\chi_{12}$ values obtained from the melting point depression are dependent on the molar mass of PVC, varying from -0.102 to -0.028 , indicating that the pair is miscible in the melt.

In this paper, we report the study on the miscibility of blends of PAM, PNIPAAm, PTBAA, PDEAA e PDMAA with PEG, using differential scanning calorimetry (DSC). The Flory-Huggins interaction parameters $\left(\chi_{12}\right)$ were determined by the melting point depression method.

\section{Experimental}

\subsection{Materials}

PAM, PNIPAAm, PTBAA, PDMAA and PDEAA were synthesized via free radical mechanism, under nitrogren atmosphere, according to the method described by Freitas and Cussler [1].

Monomers (Aldrich and Polyscience) and the initiators, ammonium persulfate, sodium metabisulfite (Reagen), and 2,2'-azobisisobutyronitrile (Polyscience), analytical grade, were used as received.

PEG (Aldrich), $2000 \mathrm{~g} \cdot \mathrm{mol}^{-1}$, was used as received, without additional purification.

The weight-average molecular weight $\left(\mathrm{M}_{\mathrm{W}}\right)$ of amorphous homopolymers was determined by light scattering using a Brookhaven Instruments equipment.

\subsection{Blends Preparation}

Binary blends of varying compositions were prepared by casting from water and methanol solutions. To ensure complete removal of the solvent, the blends were kept under vacuum at $41^{\circ} \mathrm{C}$ for ten days.

\subsection{Blends Characterization and Determination of Crystallization Temperatures by DSC}

The DSC curves for homopolymers and blends were obtained on a DSC-50 Shimadzu module. Samples weights were maintained in the range of $10 \mathrm{mg}$. All experiments were performed under helium flow of $70 \mathrm{~mL} \cdot \mathrm{min}^{-1}$. The samples were heated from ambient to $210^{\circ} \mathrm{C}$ at a rate of $20^{\circ} \mathrm{C} \cdot \mathrm{min}^{-1}$, held at this temperature for $10 \mathrm{~min}$ to eliminate thermal history. After cooling the samples to $-20^{\circ} \mathrm{C}$ at a rate of $20^{\circ} \mathrm{C} \cdot \mathrm{min}^{-1}$, they were heated again to $210^{\circ} \mathrm{C}$ at $10^{\circ} \mathrm{C} \cdot \mathrm{min}^{-1}$.

The glass transition temperature and the melting enthalpies $\left(\Delta H_{m}\right)$ values were taken from the second heating scan. The cooling scan was used to select the crystallization temperatures.

\subsection{Isothermal Crystallization}

Isothermal crystallization was performed on a DSC-50 Shimadzu module based on the Hoffman-Weeks method [22]. Samples weights of $10 \mathrm{mg}$ were heated from $25^{\circ} \mathrm{C}$ to $200^{\circ} \mathrm{C}$ at a rate of $20^{\circ} \mathrm{C} \cdot \mathrm{min}^{-1}$, held at this temperature for $5 \mathrm{~min}$, rapidly cooled (cooling rate $40^{\circ} \mathrm{C} \cdot \mathrm{min}^{-1}$ ) to the desired crystallization temperature $\left(T_{c}\right)$, maintained at this temperature for $2 \mathrm{~min}$, and then cooled to $10^{\circ} \mathrm{C}$ at a rate of $20^{\circ} \mathrm{C} \cdot \mathrm{min}^{-1}$. After that, the samples were heated to $200^{\circ} \mathrm{C}$, at a rate of $20^{\circ} \mathrm{C} \cdot \mathrm{min}^{-1}$, for the measurement of the $T_{m}$. This procedure was repeated for different crystallization temperatures.

\subsection{Scanning Electron Microscopy (SEM)}

SEM micrographs of the blends were obtained using a JEOL JSM-5410 microscope and the samples were fractured in nitrogen and covered by sputtering with a $\mathrm{Au} / \mathrm{Pd}$ alloy.

\subsection{Density Measurements}

Density measurements of each homopolymer were carried out using a picnometer in a non-solvent (heptane and cyclohexane).

\section{Results and Discussion}

The weight-average molecular weight of PAM and its $\mathrm{N}$-alkyl substituted derivatives are, as seen in Table 1, at the same order of magnitude.

Density values of PAM and its $\mathrm{N}$-alkyl substituted derivatives are showed in Table 2.

It's shown in Figure 1 DSC curves of blends with 20

Table 1. Weight-average molecular weight of PAM and its $\mathrm{N}$-alkyl substituted derivatives

\begin{tabular}{cccccc}
\hline Homopolymer & PAM & PNIPA Am & PTBAA & PDMAA & PDEAA \\
\hline $\mathrm{M}_{\mathrm{W}} \times 10^{-5} / \mathrm{g} \cdot \mathrm{mol}^{-1}$ & 2.53 & 1.20 & 2.07 & 2.74 & 1.15 \\
\hline
\end{tabular}

Table 2. Density values of homopolymers.

\begin{tabular}{ccccccc}
\hline Polymer & \multicolumn{1}{c}{ PAM } & PNIPAAm PTBAA & PDMAA & PDEAA & PEG \\
\hline $\begin{array}{c}\text { Density/ } \\
\mathrm{g} \cdot \mathrm{mL}^{-1}\end{array}$ & 1.05 & 0.97 & 0.89 & 0.89 & 0.89 & 1.31 \\
\hline
\end{tabular}


$\mathrm{wt} \%, 40 \mathrm{wt} \%, 60 \mathrm{wt} \%$ and $80 \mathrm{wt} \%$ PEG. $T_{g}$ values are listed in Table 3. A single $T_{g}$ is observed for all blends and it does not change appreciably with the composition, showing values around $T_{g}$ of the amorphous polymer (PAM and its $N$-alkyl substituted derivatives), suggesting that the amorphous phase of the blend is rich in this component. The blends also show a single endothermic peak due to the melting of crystalline phase (PEG).

Figure 2 shows scanning electron micrographs of PAM, PEG and PAM/PEG blends in various compositions. It is observed that the crystal sizes are dependent on the amorphous polymer concentration. As the amorphous polymer concentration increases, PEG crystalline phase size decreases (Table 4). It is known that the kinetics of crystallization of the crystalline component in a blend is affected by the presence of the amorphous polymer [27,28]. Both, the overall kinetic rate and the spherulites growth rate decrease significantly. Changes on crystallization behavior are due to low mobility of PEG related with $T_{g}$ of the blends and with the possibility of favorable interactions between PEG and the amorphous polymer.

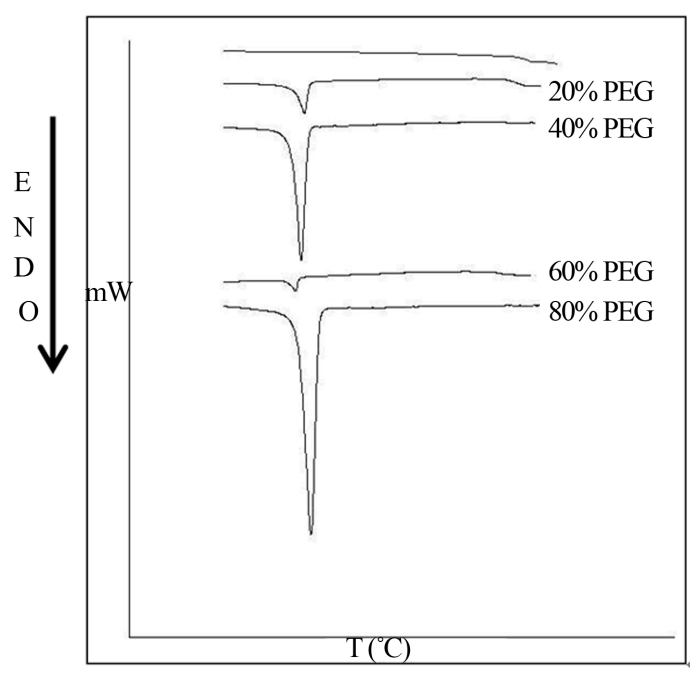

Figure 1. DSC curves for PAM/PEG.

Table 3. $T_{g}$ values of PAM/PEG and their blends.

\begin{tabular}{cccccc}
\hline $\begin{array}{r}\text { PEG/ } \\
\% . w^{-1}\end{array}$ & $\begin{array}{c}\text { PMA/ } \\
\text { PEG }\end{array}$ & $\begin{array}{c}\text { PNIPAAm/ } \\
\text { PEG }\end{array}$ & $\begin{array}{c}\text { PTBAA/ } \\
\text { PEG }\end{array}$ & $\begin{array}{c}\text { PDMAA/ } \\
\text { PEG }\end{array}$ & $\begin{array}{c}\text { PDEAA/ } \\
\text { PEG }\end{array}$ \\
\hline 0 & 188 & 142 & 128 & 111 & 91 \\
20 & 178 & 133 & 84 & 98 & 88 \\
40 & 174 & 126 & 84 & 90 & 85 \\
60 & 166 & 126 & 87 & 83 & 83 \\
80 & 163 & 126 & 83 & 79 & 83 \\
100 & $-52^{*}$ & $-52^{*}$ & $-52^{*}$ & $-52^{*}$ & $-52^{*}$ \\
\hline
\end{tabular}

*Silva et al. [8].

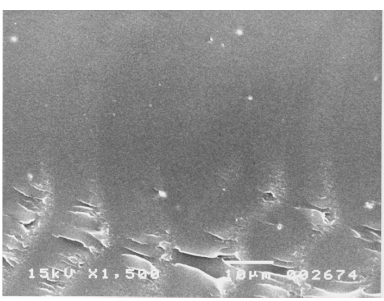

(a)

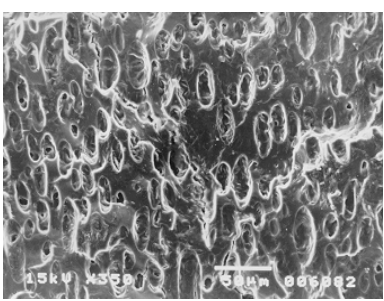

(c)

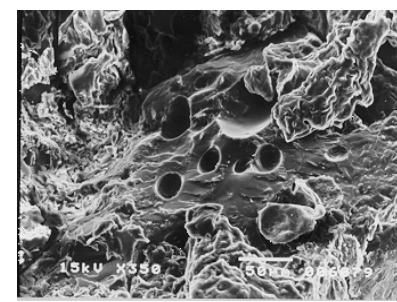

(e)

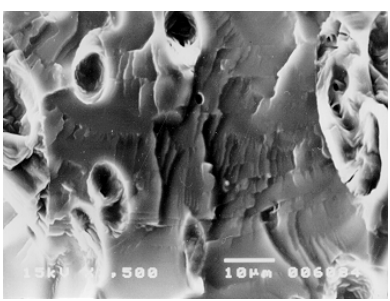

(b)

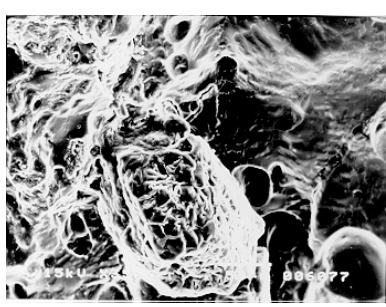

(d)

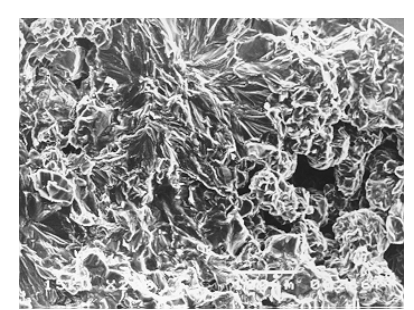

(f)
Figure 2. SEM micrographs; (a) pure PAM; (b) 20\% PEG; (c) $40 \%$ PEG; (d) 60\% PEG; (e) 80\% PEG; (f) pure PEG.

Table 4. PEG crystals average diameters $\left(d_{m}\right)$ of PAM/PEG blends.

\begin{tabular}{ccccc}
\hline $\mathrm{PAM} / \% \mathrm{~m} \cdot \mathrm{m}^{-1}$ & 20 & 40 & 60 & 80 \\
$\mathrm{~d}_{\mathrm{m}} / \mu \mathrm{m}$ & 24 & 24 & 20 & 14 \\
\hline
\end{tabular}

\section{Determination of Flory-Huggins Parameter}

In blends in which at least one component is crystallizable, the melt point depression of the crystalline phase relative to its melting point provides additional evidence of miscibility. The melting point of a polymer is affected not only by the thermodynamic factors but also by the morphological aspects such as crystalline lamellar thickness. As described by the Flory-Huggins theory, the equilibrium melting point should be used to separate morphological effect from thermodynamic effect in discussing the melt point depression [29].

Morphological effects are associated with changes in crystal perfection or geometry and with different thermal history of the samples. The contribution of such morphological effects can usually be removed by constructing a Hoffman-Weeks [22] plot by using melting data for PEG and for blends isothermally crystallized at different temperatures $\left(T_{c}\right) ; T_{m e}$ is determinated by the extrapolation of the experimental curve of $T_{m}$ versus $T_{c}$ to theo- 
retical curve, $T_{m}=T_{c}$.

Thermodynamic considerations predict that chemical potential of a crystallizable polymer will decrease caused by the addition of the miscible diluent [28]. The expression to describe the dependence of the melting point depression due only to thermodynamic effects on the blends composition is given, according to the Flory-Huggins theory modified by Nishi-Wang, by Equation (1) [20,21].

$$
\frac{1}{T_{m e}}-\frac{1}{T_{m e}^{0}}=-\frac{R V_{2 u}}{\Delta H_{2 u} V_{1 u}}\left[\frac{\ln \phi_{2}}{m_{2}}+\left(\frac{1}{m_{2}}-\frac{1}{m_{1}}\right) \phi_{1}+\chi_{12} \phi_{1}^{2}\right]
$$

$T_{m e}$ e $T_{m e}^{0}$ are the equilibrium melting temperature of PEG in blends and pure PEG, respectively. Subscripts $1 \mathrm{e}$ 2 are referred to the crystallizable and non-crystallizable polymers, $V_{u}$ is the molar volume of the repeating unit, $\Delta H_{u}$ is the heat of fusion of the perfectly crystallizable polymer per mole of the repeat unit, $m$ is the degree of polymerization; $\phi$ are the volume fractions, $R$ is the universal gas constant, and $\chi_{12}$ is the polymer-polymer interaction parameter.

Figure 3 shows the Hoffman-Weeks plots for isothermally crystallized blends.

Table 5 summarizes the equilibrium melting temperatures of PEG in the blends $\left(T_{m e}\right)$. For pure PEG, equilibrium melting point $\left(T_{m e}^{0}\right)$ was determined as $57^{\circ} \mathrm{C}$. In general, $T_{m e}$ values showed a slight decreasing tendency relative to $T_{m e}^{0}$ value as the concentration of the amorphous component increases.

Table 6 shows $\phi_{1}$ and $\phi_{2}$ values used to calculate $\chi_{12} . R$ and $\Delta H$ values were $8.31 \mathrm{~J} \cdot \mathrm{K}^{-1} \cdot \mathrm{mol}^{-1}$ and $7.90 \mathrm{~K} \cdot \mathrm{J} \cdot \mathrm{mol}^{-1}$, respectively.

In Figure 4 and in Table 7, $\chi_{12}$ values are represented as a function of PEG composition.

For all systems, $\chi_{12}$ values are dependent on the blend composition. Avella [25] and Yoo [30] attribute the dependence of $\chi_{12}$ on the blend composition to morphological and kinetics factors such as recrystallization, phase segregation, etc. Painter et al. [31] proposed that this effect results from the strong interactions between the components as hydrogen bonding observed in poly(vinyl

Table 5. Equilibrium melting temperatures of PEG in the blends.

\begin{tabular}{cccccc}
\hline \multicolumn{5}{c}{$T_{m e}{ }^{\circ} \mathrm{C}$} \\
\hline $\begin{array}{c}\text { PEG/ } \\
\% \mathrm{~m} \cdot \mathrm{m}^{-1}\end{array}$ & $\begin{array}{c}\text { PAM/ } \\
\text { PEG }\end{array}$ & $\begin{array}{c}\text { PIPAA/ } \\
\text { PEG }\end{array}$ & $\begin{array}{c}\text { PTBAA/ } \\
\text { PEG }\end{array}$ & $\begin{array}{c}\text { PDMAA/ } \\
\text { PEG }\end{array}$ & $\begin{array}{c}\text { PDEAA/ } \\
\text { PEG }\end{array}$ \\
\hline 20 & 54 & 52 & 53 & 56 & 52 \\
40 & 56 & 56 & 55 & 53 & 55 \\
60 & 56 & 56 & 56 & 55 & 56 \\
80 & 56 & 56 & 56 & 56 & 56 \\
\hline
\end{tabular}

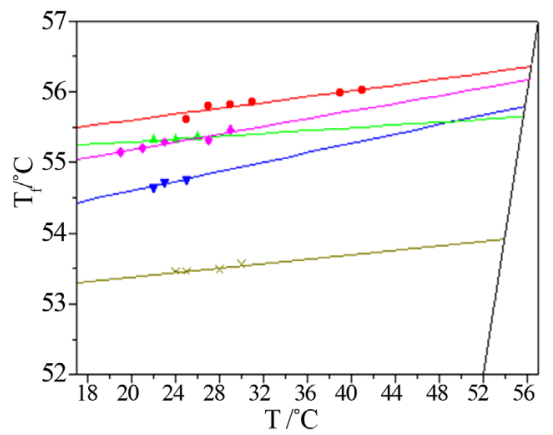

(a)

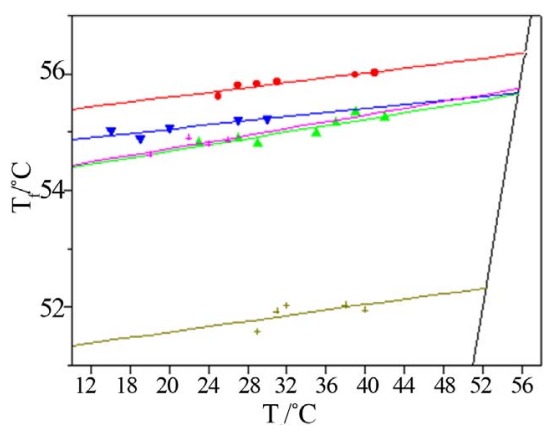

(b)

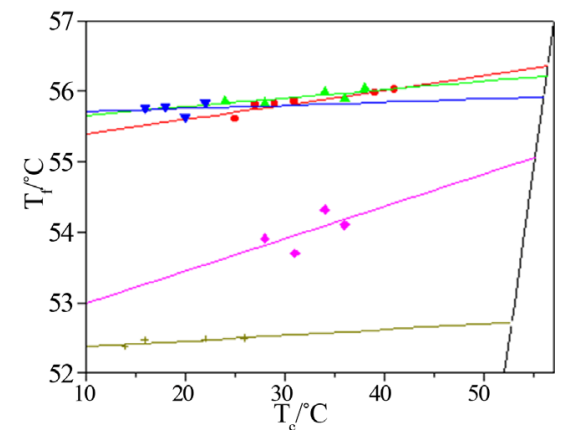

(c)

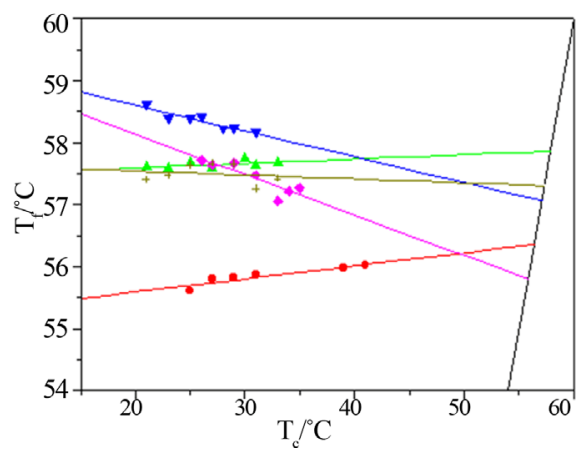

(d)

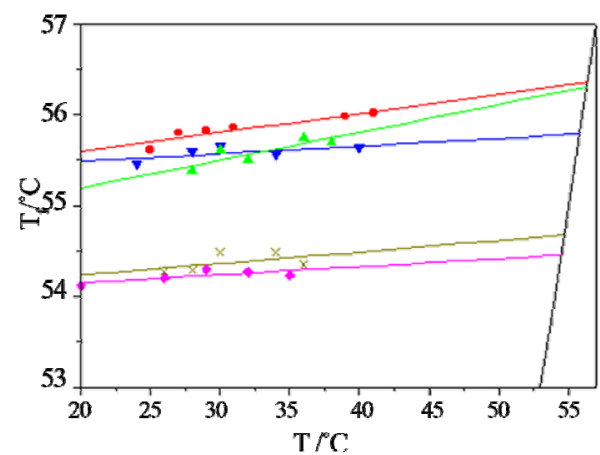

(e)

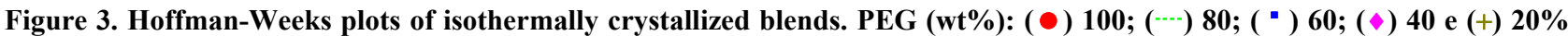
$\mathrm{m} \cdot \mathrm{m}^{-1}$; (a) PAM/PEG; (b) PNIPAAm/PEG; (c) PTBAA/PEG; (d) PDMAA/PEG; (e) PDEAA/PEG. 
Table 6. $\phi_{1}$ and $\phi_{2}$ values.

\begin{tabular}{ccccccccccccc}
\hline & \multicolumn{2}{c}{ PAM/PEG } & \multicolumn{2}{c}{ PIPAA/PEG } & \multicolumn{2}{c}{ PTBAA/PEG } & \multicolumn{2}{c}{ PDMAA/PEG } & \multicolumn{2}{c}{ PDEAA/PEG } \\
\cline { 2 - 11 } PEG $/ \% \mathrm{~m} \cdot \mathrm{m}^{-1}$ & $\phi_{1}$ & $\phi_{2}$ & $\phi_{1}$ & $\phi_{2}$ & $\phi_{1}$ & $\phi_{2}$ & $\phi_{1}$ & $\phi_{2}$ & $\phi_{1}$ & $\phi_{2}$ \\
\hline 20 & 0.84 & 0.16 & 0.85 & 0.15 & 0.85 & 0.15 & 0.85 & 0.15 & 0.86 & 0.14 \\
40 & 0.66 & 0.34 & 0.67 & 0.33 & 0.69 & 0.31 & 0.69 & 0.31 & 0.70 & 0.30 \\
60 & 0.47 & 0.53 & 0.48 & 0.53 & 0.49 & 0.51 & 0.49 & 0.51 & 0.51 & 0.49 \\
80 & 0.25 & 0.75 & 0.25 & 0.75 & 0.27 & 0.73 & 0.27 & 0.73 & 0.28 & 0.72 \\
\hline
\end{tabular}

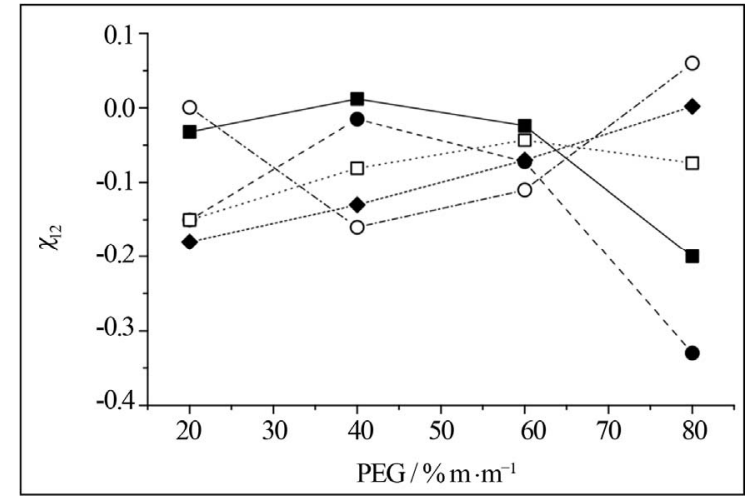

Figure 4. $\chi_{12}$ versus blends composition: (ロ) PAM/PEG, (๑) PNIPAAm/PEG, ( $\square$ ) PTBAA/PEG, (O) PDMAA/PEG e ( $\bullet)$ PDEAA/PEG.

Table 7. $\chi_{12}$ values as a function of PEG concentration.

\begin{tabular}{cccccc}
\hline & \multicolumn{5}{c}{$\chi_{12}$} \\
\cline { 2 - 6 } $\begin{array}{c}\text { PEG/ } \\
\% \mathrm{~m} \cdot \mathrm{m}^{-1}\end{array}$ & $\begin{array}{c}\text { PAM/ } \\
\text { PEG }\end{array}$ & $\begin{array}{c}\text { PIPAA/ } \\
\text { PEG }\end{array}$ & $\begin{array}{c}\text { PTBAA/ } \\
\text { PEG }\end{array}$ & $\begin{array}{c}\text { PDMAA/ } \\
\text { PEG }\end{array}$ & $\begin{array}{c}\text { PDEAA/ } \\
\text { PEG }\end{array}$ \\
\hline 20 & -0.032 & -0.15 & -0.15 & $7.2 \times 10^{-4}$ & -0.18 \\
40 & 0.012 & -0.015 & -0.081 & -0.16 & -0.13 \\
60 & -0.024 & -0.072 & -0.043 & -0.11 & -0.070 \\
80 & -0.20 & -0.33 & -0.074 & 0.060 & $2.0 \times 10^{-3}$ \\
\hline
\end{tabular}

phenol) and poli(ethylene-co-acrylic acid) blends. Lee et al. [32] studying, by DSC, blends of polystyrene and polybutadiene, found $\chi_{12}$ values in the range of 0.0040 to 0.0102 , depending on the blend composition and on the molar mass of the homopolymers. Linares and Acosta [33] studied PVDA/PVA and PVDF/PMMA blends and found $\chi_{12}$ values in the range of -0.164 to $2.025 \times 10^{-3}$ and of -0.153 to $2.201 \times 10^{-3}$, respectively, indicating, according to the authors, that these systems are partially miscible.

Blends of poly(vinyl alcohol) and Nylon 6 were studied by Koulouri and Kallitsis [34], through dynamic-mechanical analysis (DMA), DSC and the Nishi-Wang equation to determine Flory-Huggins parameters. The results showed a single $T_{g}$ and the $\chi_{12}$ value was -0.05 , suggesting miscibility. Others $\chi_{12}$ values and their analysis as criterion of miscibility for blends can be found in Zhang et al. [28], Marcos et al. [35], and Cimmino et al. [24].

Miscibility was investigated in blends of poly(butylene succinate) (PBSU) and poly(vinyl phenol) (PVPh) by Qiu et al. [36]. The existence of single composition dependent glass transition temperature and the negative values of $\chi_{12}$, calculated using the Nishi-Wang equation, indicate that PBSU/PVPh blends are thermodynamically miscible in the melt.

Oréfice et al. [29] determined the degree of interaction between the components of a polycarbonate-polystyrene blend through the Flory-Huggins interaction parameter. The results showed that blends with higher content of polycarbonate tend to present $\chi_{12}$ closer to the critical values, suggesting greater compatibility in these compositions.

High molecular weight samples of the novel biodegradable polyester poly(ethylene sebacate) (PESeb) with poly(4-vinyl phenol) (PVPh) blends were studied, with respect to miscibility, by Papageorgiou et al. [37]. A single glass transition temperature intermediate to those of pure components was observed in all blends. Melting point depression was observed with increasing content of the amorphous polymer. The equilibrium melting points were estimated using Hoffmann-Weeks extrapolation. The interaction parameter was calculated and it was found to be $\chi_{12}=-1.3$. Blends miscibility was attributed to the formation of hydrogen bonds between the hydroxyl groups of PVPh and carbonyl groups of PESeb.

In the present work, $\chi_{12}$ values are dependent on the blend composition and are near zero or slightly negatives (Table 7), suggesting partial miscibility between PEG and the amorphous polymers in the melting, maybe as a result of interactions through hydrogen bonds. Additionally, $T_{g}$ behavior and SEM micrographs corroborate this result.

\section{Conclusion}

Binary blends of polyacrylamide and some of its $\mathrm{N}$-alkyl substituted derivatives with PEG, obtained by co-dissolution method, are partially miscible, as demonstrated by the smooth lowering of $T_{g}$ values relative to the $T_{g}$ value of the pure amorphous component. The polymer-polymer 
interaction parameters obtained from thermodynamic melting temperature depression analysis are slightly negative and close to zero, suggesting partial miscibility among the components. Furthermore, for all blends studied, there is an endothermic peak corresponding to the melting of the PEG crystalline phase. For all blends studied, SEM micrographs indicate the presence of PEG crystalline phase.

\section{Acknowledgements}

The authors thank the Brazilian Agencies CNPq, CAPES and FAPEMIG for financial support.

\section{REFERENCES}

[1] R. F. S. Freitas and E. L. Cussler, Chemical Engineering Science, Vol. 42, 1987, pp. 97-103. doi:10.1016/0009-2509(87)80213-0

[2] R. G. Sousa, R. F. S. Freitas and W. F. Magalhães, Polymer, Vol. 39, 1998, pp. 3815-3819. doi:10.1016/S0032-3861(97)10341-X

[3] W. M. Thomas and D. W. Wang, "Encyclopedia of Polymer Science Engineering," John Wiley \& Sons, New York, 1988.

[4] F. Zeng, X. Zheng and Z. Tong, Polymer, Vol. 39, 1998, pp. 1249-1251. doi:10.1016/S0032-3861(97)00471-0

[5] J. Klein and R. Heitzmann, Die Makromolekulare Chemie, Vol. 179, 1978, pp. 1895-1904. doi:10.1002/macp.1978.021790803

[6] E. A. Smith and F. W. Oehme, Journal of Chromatographic. Science, Vol. 31, 1993, pp. 192-195. doi:10.1093/chromsci/31.5.192

[7] S. C. S. Teixeira, Proceedings of the 3rd Congresso Brasileiro de Polímeros, Rio de Janeiro, 30 October-2 November 1995, p. 925.

[8] M. E. S. R. Silva, E. R. Dutra, V. Mano and J. C. Machado, Polymer Degradation and Stability, Vol. 67, 2000, pp. 491-495. doi:10.1016/S0141-3910(99)00149-4

[9] A. S. Hoffman, Advanced Drug Delivery Reviews, Vol. 54, 2002, pp. 3-12. doi:10.1016/S0169-409X(01)00239-3

[10] T. R. Hoare and D. S. Kohane, Polymer, Vol. 49, 2008, pp. 1993-2007. doi:10.1016/j.polymer.2008.01.027

[11] M. R. Jin, C. F. Wu, P. Y. Lin and W. J. Hou, Journal of Applied Polymer Science, Vol. 56, 1995, pp. 285-288. doi:10.1002/app.1995.070560220

[12] H. Kanazawa, Y. Kashiwase, K. Yamamoto, Y. Matsushima, A. Kikuchi, Y. Sakurai and T. Okano, Analytical Chemistry, Vol. 69, 1997, pp. 823-830. doi:10.1021/ac961024k

[13] G. C. Tavares, M. E. S. R. Silva, R. G. Sousa and R. F. S. Freitas, Macromolecular Symposia, Vol. 319, 2012, pp. 10-14. doi:10.1002/masy.201200009

[14] M. A. Silva, "Blendas de poli(óxido de etileno) com poli(epicloridrina) e com poli(epicloridrina-co-óxido de etileno): Comportamento de fases, miscibilidade e morfolo- gia," M.Sc. Dissertation, UNICAMP, Campinas, 1995.

[15] A. C. Quental, F. P. Carvalho, E. S. Tada and M. I. Felisberti, Química Nova, Vol. 33, 2012, pp. 438-436. doi:10.1590/S0100-40422010000200035

[16] D. S. Rosa, C. G. F. Guedes, C. M. Oliveira and M. I. Felisberti, Journal of Polymers and the Environment, Vol. 16, 2008, pp. 230-240. doi:10.1007/s10924-008-0114-7

[17] D. F. Parra, J. Fusaro, F. Gaboardi and D. S. Rosa, Polymer Degradation and Stability, Vol. 91, 2006, pp. 19541959. doi:10.1016/j.polymdegradstab.2006.02.008

[18] H. J. Chiu, Polymer, Vol. 46, 2005, pp. 3906-3913. doi:10.1016/j.polymer.2005.03.032

[19] M. A. Silva, M. A. De Paoli and M. I. Felisberti, Polymer, Vol. 39, 1998, pp. 2551-2556. doi:10.1016/S0032-3861(97)00574-0

[20] T. Nish, T. T. Wang and T. K. Kwei, Macromolecules, Vol. 8, 1975, pp. 227-234.

[21] P. J. Flory, "Principles of Polymer Chemistry," Cornell University Press, Ithaca, 1953.

[22] J. D. Hoffman and J. J. Weeks, Journal of Chemical Physics, Vol. 37, 1962, pp. 1723-1741. doi:10.1063/1.1733363

[23] M. M. Cortazar, M. E. Calahorra and G. M. Guzman, European Polymer Journal, Vol. 18, 1982, pp.165-166. doi:10.1016/0014-3057(82)90196-3

[24] S. Cimmino, E. Di Pace, E. Martuscelli and C. Silvestre, Die Makromolekulare Chemie, Vol. 191, 1990, pp. 24472454. doi:10.1002/macp.1990.021911022

[25] M. Avella and E. Martuscelli, Polymer, Vol. 29, 1988, pp. 1731-1737. doi:10.1016/0032-3861(88)90384-9

[26] S. M. S. Neiro, D. C. Dragunsky, A. F. Rubira and E. C. Muniz, European Polymer Journal, Vol. 36, 2000, pp. 583-589. doi:10.1016/S0014-3057(99)00082-8

[27] G. Dreezen, Z. Fang and G. Groeninckz, Polymer, Vol. 40, 1999, pp. 5907-5917. doi:10.1016/S0032-3861(98)00809-X

[28] L. L. Zang, S. H. Goh, S. Y. Lee and G. R. Hee, Polymer, Vol. 41, 2000, pp. 1429-1439. doi:10.1016/S0032-3861(99)00320-1

[29] R. L. Oréfice, W. L. Vasconcelos and M. A. S. Moraes, Polímeros: Ciência e Tecnologia, Vol. 14, 2004, pp. 129133. doi:10.1590/S0104-14282004000200017

[30] H. Y. Yoo, S. Umemoto, T. Kikutani and N. Okui, Polymer, Vol. 35, 1994, pp. 117-122. doi:10.1016/0032-3861(94)90058-2

[31] P. C. Painter, S. L. Shenoy, D. E. Bhagwagar, J. Fishburn and M. M. Coleman, Macromolecules, Vol. 24, 1991, pp. 5623-5629. doi:10.1021/ma00020a022

[32] H. S. Lee, W. N. Kim and C. M. Burns, Journal of Applied Polymer Science, Vol. 64, 1997, pp. 1301-1308. doi:10.1002/(SICI)1097-4628(19970516)64:7<1301::AID -APP9>3.0.CO;2-N

[33] A. Linares and J. L. Acosta, Journal of Applied Polymer Science, Vol. 67, 1998, pp. 997-1004. doi:10.1002/(SICI)1097-4628(19980207)67:6<997::AIDAPP5>3.0.CO;2-H 
[34] E. G. Koulouri and J. K. Kallitsis, Polymer, Vol. 39, 1998, pp. 2373-2379. doi:10.1016/S0032-3861(97)00542-9

[35] J. I. Marcos, E. Orlandi and G. Zerbi, Polymer, Vol. 31, 1990, pp. 1899-1903. doi:10.1016/0032-3861(90)90014-P

[36] Z. Qiu, K. Motonori, I. Takayuki and N. Toshio, Polymer,
Vol. 44, 2003,pp. 8111-8117. doi:10.1016/i.polymer.2003.10.030

[37] G. Z. Papageorgiou, D. N. Bikiaris and C. G. Panayiotou, Polymer, Vol. 52, 2011, pp. 4553-4561. doi:10.1016/j.polymer.2011.07.050 